\title{
Assessment of Rainwater Harvesting Reticulation Systems to Reduce High Management Costs in Household Buildings
}

\author{
James Shikuku1 ${ }^{*}($ D) Gerryshom Munala1, Bernard Mugwima1, Teckla Muhoro², \\ Andrew Gremley ${ }^{3}$, Victor Nyakundi ${ }^{1}$, Muhammad Ali ${ }^{1}$ \\ ${ }^{1}$ Centre for Urban Studies, Jomo Kenyatta University of Agriculture and Technology, Nairobi, Kenya \\ ${ }^{2}$ Department of Construction Management, Jomo Kenyatta University of Agricultureand Technology, Nairobi, Kenya \\ ${ }^{3}$ Pharos Architects Ltd., Nairobi, Kenya \\ Email: ^james.shikuku@jkuat.ac.ke
}

How to cite this paper: Shikuku, J., Munala, G., Mugwima, B., Muhoro, T., Gremley, A., Nyakundi, V. and Ali, M. (2020) Assessment of Rainwater Harvesting Reticulation Systems to Reduce High Management Costs in Household Buildings. Natural Resources, 11, 156-167.

https://doi.org/10.4236/nr.2020.114010

Received: February 26, 2020

Accepted: April 20, 2020

Published: April 23, 2020

Copyright $\odot 2020$ by author(s) and Scientific Research Publishing Inc. This work is licensed under the Creative Commons Attribution International License (CC BY 4.0).

http://creativecommons.org/licenses/by/4.0/

(c) (i) Open Access

\begin{abstract}
Rainwater harvesting provides an important alternative source of water in household buildings which increases water security in urban areas. However, high energy cost consumption by the rainwater harvesting systems results in higher management costs which may derail the investment viability of these systems in households. This prompted this study to establish ways through which the management cost of rainwater harvesting systems can be minimized in household buildings. A survey of 200 households from Greenspan, Komarock, Utawala, Kileleshwa and Runda in Nairobi County was undertaken as well as data on the type of rainwater harvesting systems, their operation and maintenance cost collected using observation checklists and questionnaires. The findings indicated that rainwater harvesting typologies 1, 2, 4 and 5 had their water pumped from first-level storage to the second-level storage then supplied to usage points by gravity. Whereas, typologies 3 and 6 had their water moved manually and by gravity respectively. On annual operation cost, $100 \%$ of households with typology 3 and 6 spent no money whereas, $100 \%, 75 \%$ and $70.6 \%$ with typology 4 and 5, 1 and 2 respectively spent Ksh. 1 - 5000. On annual maintenance cost, 100\%, 93.7\% and $77.8 \%$ of households with typology 5 and 6,3 and 4 respectively spent Ksh. 1 - 5000 while $25 \%$ and $22.2 \%$ of households with typology 1 and 2 respectively spent Ksh. 5000 - 10,000. Advanced typology 6 with one-level storage point supplies rainwater to all parts of the household by gravity. This eliminates operation costs spent on energy consumption due to pumping of water, thus minimizing overall management cost spent on rainwater harvesting systems in household buildings.
\end{abstract}




\section{Keywords}

Energy Consumption, Management Cost, Rainwater Harvesting Reticulation System

\section{Introduction}

Rainwater harvesting has contributed greatly to increasing water security to governments and individuals living in urban and peri-urban areas [1]. It has therefore been identified as an important alternative source of water in household buildings. However, high energy inefficiency of rainwater harvesting systems which translates to high management costs may jeopardize the feasibility of this system as an important source of water in households [2].

Amongst other benefits, rainwater harvesting is an easily understood technique that collects clean water for domestic functions in households. This technology is done using locally available techniques and material and results in water that is socially acceptable [3]. Rainwater harvesting is the main water conservation method in arid areas which is stored in underground or ground surface storage tanks and in water pans [4]. Rainwater used in buildings and building complexes reduces the demand for water supplied by the municipal. It saves energy by reducing the energy consumed for pumping municipal water and mitigate flooding in the impervious urban and peri-urban environment [5]. It helps in reducing social pressure on the urban population when used as an alternative source of water in areas affected by water scarcity challenges.

However, management costs of rainwater harvesting systems which entail operation and maintenance cost have contributed to the concerns raised about the viability of this water which complements other sources of water in households. These management costs have more often been identified as the reason why the cost outweighs the benefits [1]. Energy cost efficiency of rainwater harvesting systems installed with pumps is similar to that of waste water recycling systems and only becomes competitive with the elimination of pumps [2]. Apart from the money spent on acquiring the pump, electricity costs account for about $40 \%$ of the overall cost of the pumping system [6].

The conventional rainwater harvesting system found in most of the households is suited for non-potable functions such as garden irrigation and exterior washing. It is difficult and costly to retrofit it and accrue high maintenance costs where it is pumped back to the household for potable functions. These rainwater harvesting technologies have led to long payback periods due to additional degrading (operation and maintenance) costs. Therefore, there is a compelling reason to come up with an affordable multi-beneficiary rainwater harvesting system configuration that will make this system to be energy cost-efficient in households [7].

Although rainwater harvesting is a long-established art in Kenya, its ability has not been fully maximized and is more often incorporated in household build- 
ings as an afterthought [6]. The high operation and maintenance cost spent on this system has also caused some confusion on the feasibility of installing this system in households [1]. This study, therefore, tries to find out how these management costs can be reduced through assessment of different orientation of rainwater harvesting reticulation systems installed in household buildings in the neighbourhoods of Nairobi County.

\section{Rainwater Reticulation System in Households}

Rainwater reticulation system is a framework consisting of gutters, supply pipes, storage tanks, overflow allowance, filters, pumps, pressure vessels, sensors/float switches and electronic controllers [8]. This system collects, conveys and stores harvested rainwater for later use for function such as washing, toilet flushing, bathing, irrigation and sometimes for potable functions [9].

Conventional household rainwater reticulation system occurs in the following two ways; 1) Rainwater is collected and stored in underground storage tanks where rainwater is directly pumped to usage points or it is first pumped into the high-level feeder tanks then flow by gravity to the household. 2) Rainwater is collected and stored in ground surface storage tanks where rainwater is directly pumped to usage points or it is first pumped into high-level feeder tanks then flow by gravity to the household [7]. The positioning and configuration of the components in the (Rainwater Harvesting) RWH reticulation system has a bearing on the energy cost consumptions in the system. More energy is consumed when water is directly pumped into the household usage points as compared to when it is pumped into the feeder tank first then flow by gravity to the household usage points. A high energy pressure pump is required to draw water from the underground rainwater collection tanks as compared to the ground surface tanks [2]. On the other hand, use of a direct rainwater collection tank as a header tank, use of large diameter pipes that reduce frictional losses and use of low-pressure pumps present the best environmental performance in the rainwater harvesting reticulation system [10].

These considerations have led to the emergence of innovative rainwater harvesting system configurations that attempt to reduce energy consumption and make them management cost-effective [7]. Centralization of the system also helps in reducing the energy cost i.e. where rainwater is used for non-potable and also treated for potable function in the household, it is advisable to combine the RWH reticulation systems to serve the house instead of installing two separate systems for potable and non-potable use. Two households connected to the same RWH system increase the use demand of the same system translating to higher economies of scale [2].

\section{Methodology}

A descriptive research design was employed with a research survey carried out in Nairobi County at Komarock, Greenspan, Utawala, Kileleshwa and Runda neighbourhoods. About 200 observation checklists and questionnaires were used to 
collect data on the configuration of the components in rainwater harvesting reticulation systems and the operation and maintenance cost of these reticulation systems. Through purposive sampling, five out of eighty-five neighbourhood were identified on the basis that they were single dwelling neighbourhoods installed with various rainwater harvesting reticulation systems. According to [11], the sampled neighbourhoods were adequate representation of neighbourhoods in Nairobi County as they were selected in accordance with the complexity of this study without any biases. These samples also cut across different socio-economic status in the County. Using stratified probability sampling Komarock, Greenspan and Kileleshwa were divided into four strata while Utawala and Runda were divided into eight strata depending on the sizes of the neighbourhood. Households and their respondents were identified from these strata using convenient sampling. The research framework of this study had been categorized into pre-field work, fieldwork and post-field work stage.

\section{Study Area}

The study was carried out in Kenya Nairobi County (coordinates -1.286389 , 36.817223) in Komarock, Greenspan, Utawala, Kileleshwa and Runda neighbourhoods as shown in Figure 1. The County has a bi-annual rainfall pattern with a mean annual rainfall of $786.5 \mathrm{~mm}$. The long rains have a mean of $899 \mathrm{~mm}$ and occur between March and May while short rains have a mean of $638 \mathrm{~mm}$ and occur between October and December [12]. Runda is a high-class leafy suburb area. Well supplied with county water from Runda Waters Limited although, households still harvest rainwater mainly for outdoor washing and

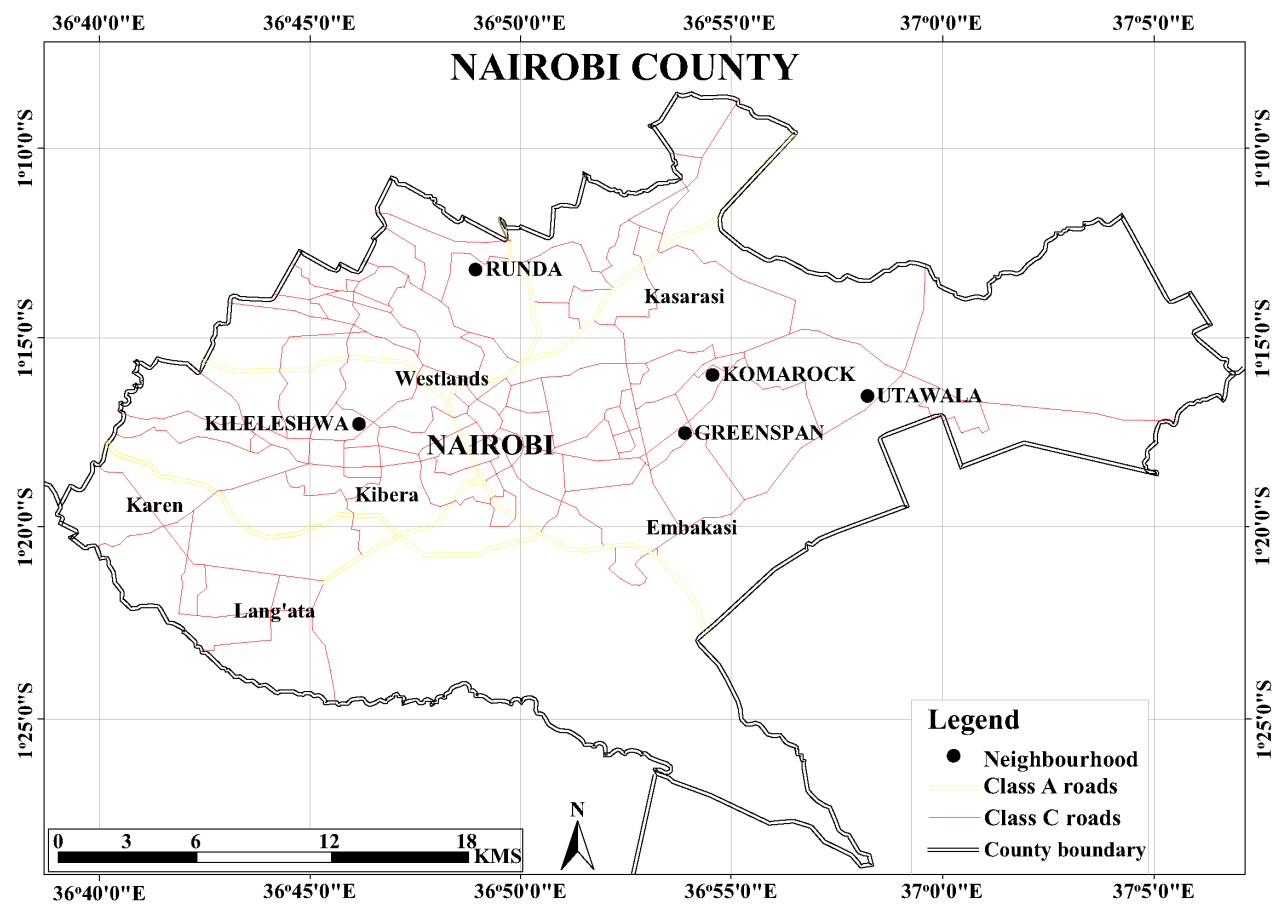

Figure 1. A map showing the distribution of sampled neighbourhoods in Nairobi County. 
compound irrigation. Kileleshwa is an upper-middle-income area whose controlled planning ensured that the area is still well supplied with county water, however, residents harvest rainwater for domestic functions to complement piped water. Utawala is a middle-class neighbourhood, one of the recently established settlements and is not fully connected and supplied with county water. Therefore, rainwater harvesting is an important alternative source of household water for domestic functions after borehole water. Komarock and Greenspan are middle-class neighbourhoods, these areas experience severe piped water shortage due to the rationing of county water that supplied to the Eastland part of Nairobi due to overcrowding of residential buildings in the area [13]. Hence, residents harvest rainwater as an important alternative source of water for domestic functions.

\section{Results and Analysis}

The collected data was analysed to determine the types and prevalence of RWH reticulation typologies in the neighbourhoods of the study area. The operation and maintenance cost of these typologies was further analysed to establish their household management cost.

1) Typologies of RWH reticulation systems

The study identified six different RWH reticulation typologies from the study area and illustrated them as shown in Table 1.

Typology 1, 2, 4 and 5 had two-level rainwater storage points. The collected rainwater water was first stored in the first level storage point then pumped to the second level storage where it was supplied to usage points by gravity. Typology 3 and 6 had one-level storage points with rainwater in typology 3 moved to usage points manually by human effort, whereas, typology 6 rainwater was supplied to the usage points naturally by gravity.

\section{2) Prevalence of typologies of RWH reticulation systems}

Assessment of household water reticulation typologies prevalence indicated that $50 \%$ of the households in Runda had typology 02 ; similarly, $34.4 \%$ had typology 03. These typologies are preferred in this neighbourhood as rainwater which is stored in the underground and ground surface storage is mainly used for outdoor compound irrigation. About $69.2 \%$ and $66.7 \%$ of households in Komarock and Greenspan respectively had typology 03 as shown in Figure 2. In these neighbourhoods, the collected rainwater is mainly used for domestic functions. Although, it is partially integrated into the households as it is directly collected and stored on the ground surface and then manually moved to usage points in the households. In Utawala, $86.1 \%$ of the households had typology 04 , which allows collected rainwater to be fully integrated into the households. This is because rainwater is one of the major sources of water for domestic functions in this neighbourhood. In Kileleshwa, $46.9 \%$ of the households had typology 03 where collected rainwater is partially integrated into the households. On the other hand, $28.6 \%$ of the households had typology 04 which allows rainwater to 
Table 1. Showing six typologies of RWH reticulation systems from the study area neighbourhoods.
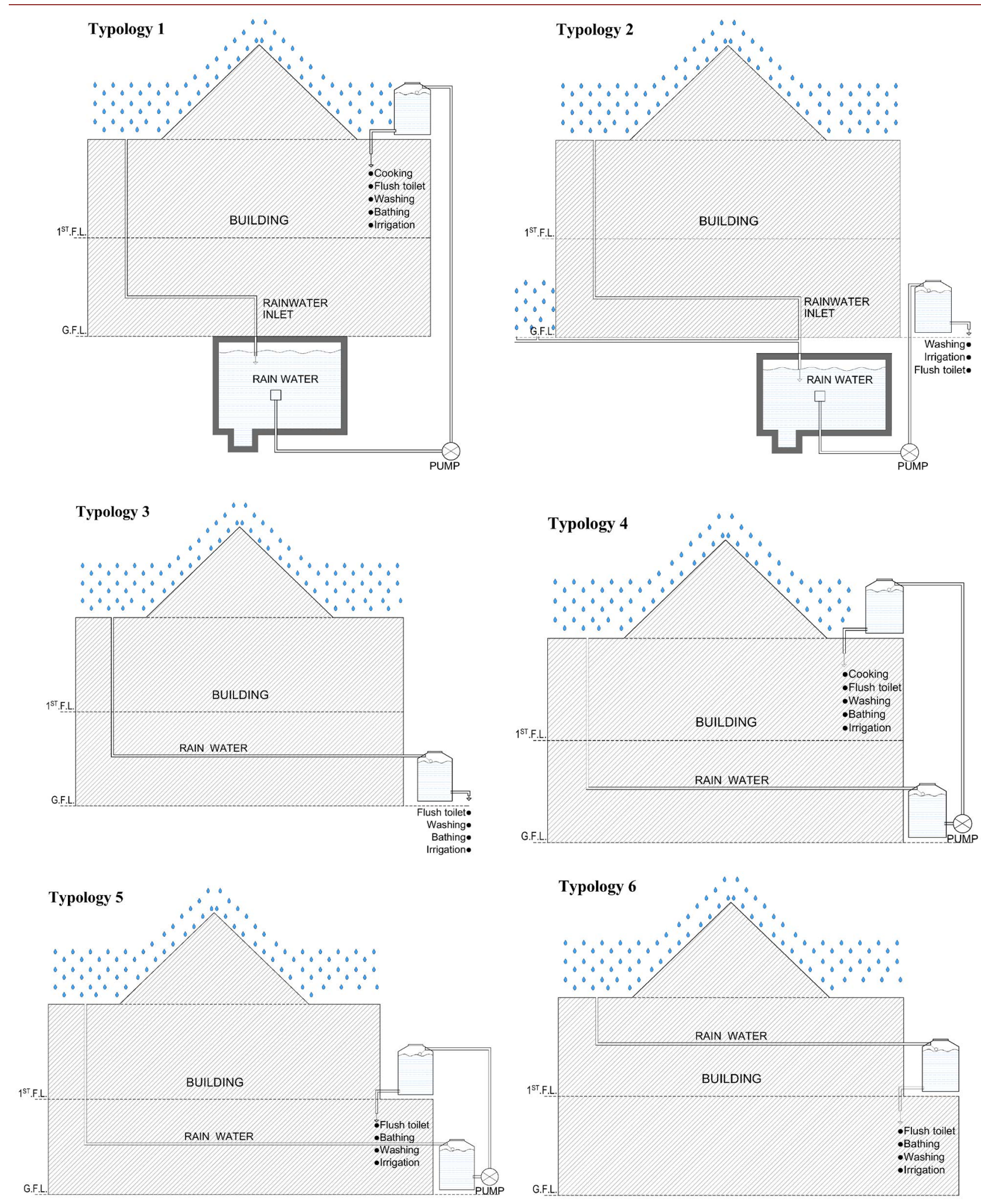

be fully integrated into the households. In this neighbourhood, rainwater mainly supplement piped county water supplied by NWSC. It is worth noting that, 7.7\% 


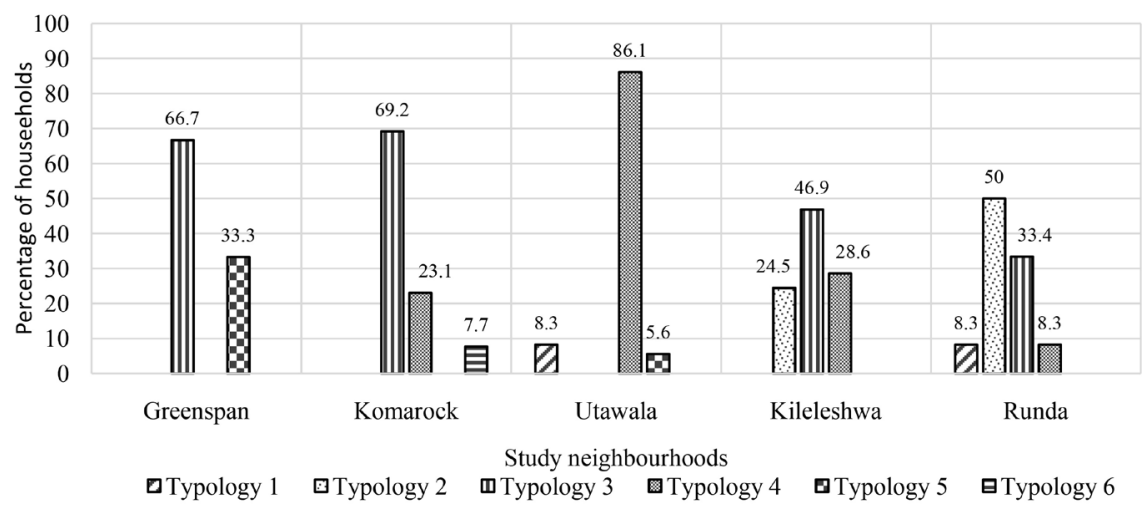

Figure 2. Prevalence of different typologies of RWH reticulation systems in the study area.

of households in Komarock had typology 06 which had a high-level rainwater storage tank. This allows collected rainwater to be partially integrated into the household although rainwater flows into the rest of the household by gravity.

\section{3) The operation cost of typologies of RWH reticulation systems}

The findings revealed that $100 \%$ of households with typology 3 and 6 spent no money on annual operation cost. On the other hand, $100 \%$ of households with typology 4 and 5 spent Ksh. 1 - 5000 on annual operation cost. Similarly, 75\% and $70.6 \%$ of households with typology 1 and 2 respectively spent Ksh. 1 - 5000 on annual operation cost whereas, $25 \%$ and $29.4 \%$ of households with typology 1 and 2 respectively spent Ksh. 5000 - 10,000 as shown in Figure 3.

Typology 3 was mainly installed in Greenspan and Komarock where households had simplified RWH reticulation systems that stored rainwater on the ground surface. This water was directly moved to usage points manually by human effort. Typology 6 found in Komarock had high-level rainwater storage on the first floor which supplied its water on the ground floor level by gravity. Typology 4 and 5 mainly occurred in Utawala where households had harvested rainwater stored on the ground surface and then pumped into a high-level header tank to flow to the rest of the house by gravity. Pumping of water in these systems directly contributed to the money spent on the operation cost.

\section{4) The Maintenance cost of typologies of RWH reticulation systems}

Analysis of maintenance cost outlined that $100 \%$ of households with typology 5 and 6 spent Ksh. 1 - 5000 annually on maintenance cost. Equally, 93.7\% and $77.8 \%$ of households with typology 3 and 4 respectively spent a similar amount of money on annual maintenance cost. Furthermore, 25\% and $22.2 \%$ of households with typology 1 and 2 spent Ksh. 5000 - 10,000 annually on operation cost as shown in Figure 4. Typology 3 and 6 mainly found in Komarock and Greenspan have only one-level storage point which minimizes the number of elements to be maintained in the RWH reticulation systems. Contrary to the latter, typology 1, 2 and 4 mainly found in Utawala, Kileleshwa and Runda all had 2 level storage points together with the pumping elements increase the number of devices to be maintained. This increases maintenance cost spent on these systems. 


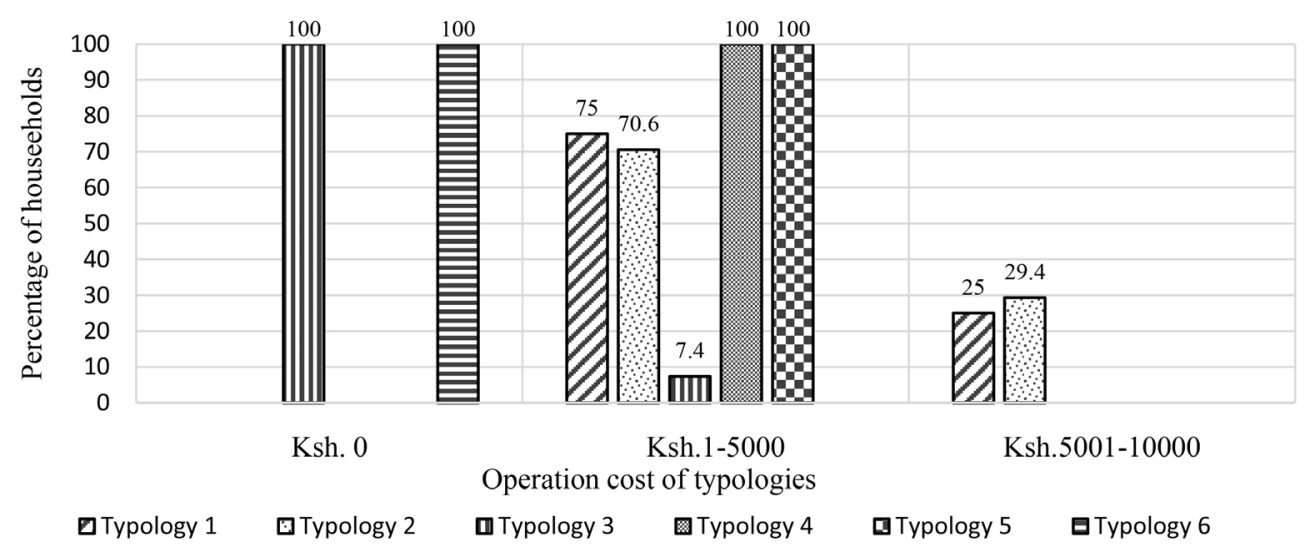

Figure 3. Distribution of operation cost of typologies of RWH reticulation systems.

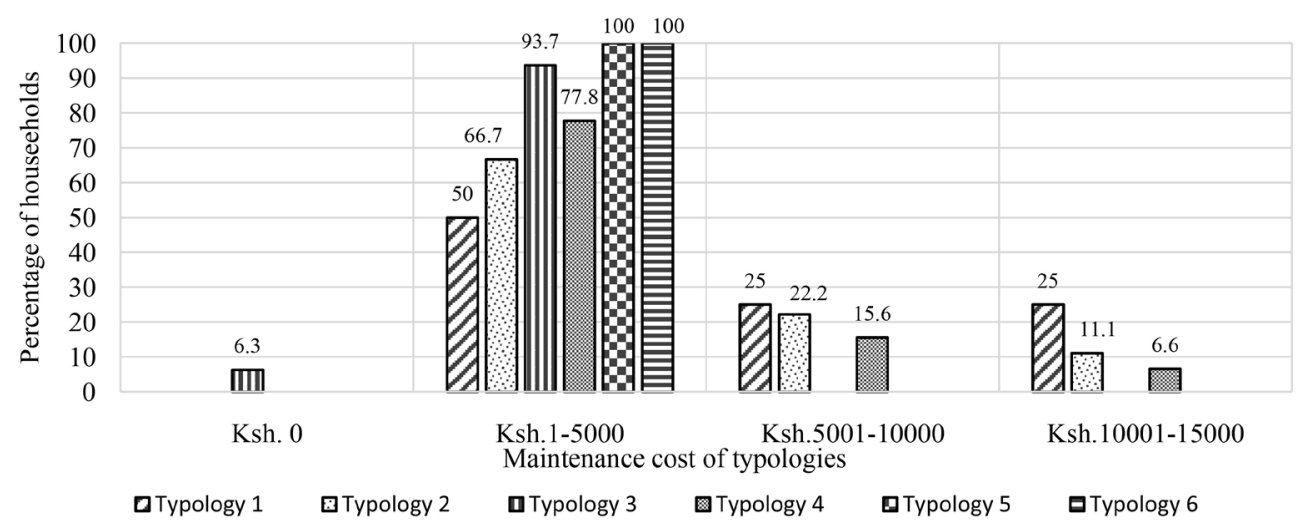

Figure 4. Distribution of maintenance cost of typologies of RWH reticulation systems.

\section{Discussions}

Typology 2 prevalent in Runda at 50\% had an underground reservoir that allows it to store a large amount of rainwater. Some of this typology had both roof and ground catchment which yield higher rainwater collection quantity, although of poor water quality [14]. However, this water was mainly used for outdoor cleaning and irrigation hence didn't require finer purification. Typology 3 had its rainwater storage on the ground surface which made it flexible to be used for all the household functions. It was prevalent in Greenspan, Komarock and Kileleshwa who had a simplified and direct rainwater collection to usage point reticulation systems. However, this rainwater was not fully integrated into the building for household functions and was manually ferried to usage points when needed. This agrees with [6] study that although rainwater harvesting technology was long established in Nairobi County its knowledge is not fully employed for optimum usage of its water in the households. RWH system should be designed together with the household building rather than just being accommodated into the building during construction or after completion for optimum use of its water. Typology 4 prevalent in Utawala at $86.1 \%$ and typology 6 allows harvested rainwater to be fully integrated into the household for domestic function through automation. The pressurized system used in typology 4 pumps 
rainwater into a header tank which in turn supplies it to the first and ground floor usage points by gravity, whereas in typology 6 , the harvested rainwater is supplied only to the ground floor usage points by gravity.

Rainwater in the RWH reticulation system's storage is moved to usage points through either a pressurized system or manually by human effort. Pressurization of the system is achieved either naturally using gravitational force or mechanically induced using pressure pumps. A system that uses pressure pumps is energy-intensive and the energy cost used in the pumping of water leads to the operation cost spent on the management of this RWH system [15]. RWH reticulation typologies 4 and 5 had two-level storage points hence a mechanical pressurized system was used to pump water from the first storage point on the ground surface to the second (header tank) to be supplied in the household. This explains why $100 \%$ of households with these typologies spent Ksh. 1 - 5000 on annual operation cost. Comparatively, $25 \%$ of households with typology 1 which had an underground rainwater first level storage point spent Ksh. 5000 - 10,000 on annual operation cost. This confirms a study by [2] that high energy pressure pump that attracts more energy cost are required to draw water from the underground tank to a high-level feeder tank. On the other hand, 100\% of households with typology 6 spent no money on the annual operation cost because the pressurized RWH reticulation system used gravitation force to draw water to usage points in the household from its high-level one-level storage point [7]. Similarly, $100 \%$ of households with typology 3 spent no money on operation cost because its water was manually moved to the usage points.

Maintenance cost is the expense used on servicing RWH reticulation systems for proper functionality. It involves money spent on cleaning tanks, replacing pumps and associated devices and repairing leakages and breakages in the system [16]. The more the elements to be serviced in a system the higher the maintenance cost. As a result, $100 \%$ and $93.7 \%$ of households with one level storage point typology 3 and 6 respectively spent Ksh. 1 - 5000 annually on maintenance cost. Whereas, $25 \%$ and $22.2 \%$ of households with two-level storage point typology 1 and 2 spent Ksh. 5000 - 10,000 annually on operation cost. These findings are in line with Australian research which established that maintenance cost for RWH systems in residential building ranged between $1-100 \$$ a year [17]. This involved corrective maintenance (repairing and replacement cost) and routine maintenance (inspection and cleaning cost).

The study recommends the adoption of a pressurized one level storage point advanced RWH reticulation systems in household buildings whose water is supplied to function points by gravity. As demonstrated from the study findings and discussion, this eliminates energy-related operation cost accrued due to the pumping of rainwater. One-level storage point system also minimizes the number of the components in the RWH system which greatly reduces the overall maintenance cost of the RWH system. This RWH reticulation system can be achieved in a number of ways as illustrated in Figure 5. Model 1 and 2 are the RWH reticulation system with their one-level storage point on the first floor and 


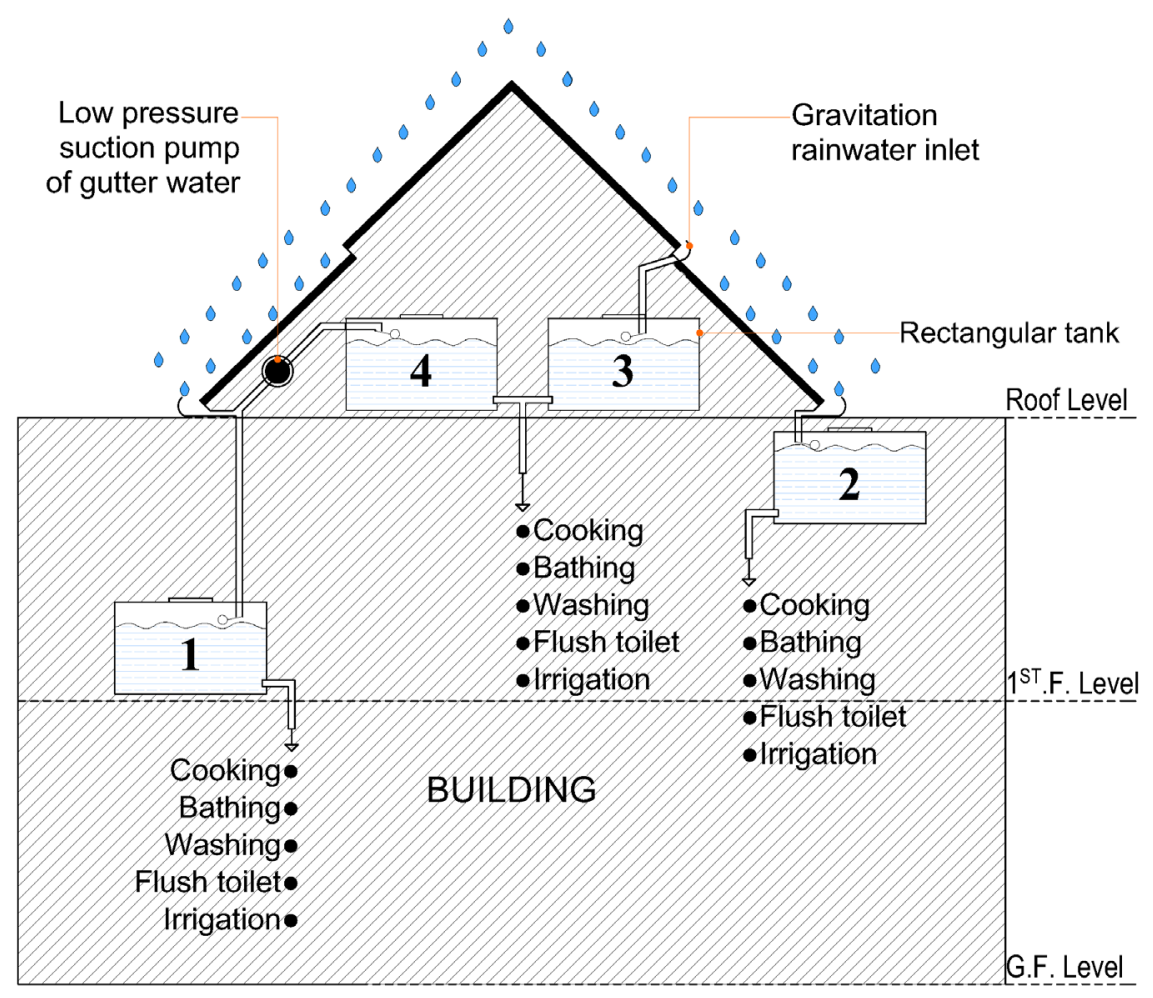

Figure 5. Recommended advanced RWH reticulation system models in households.

their storages are filled by rainwater by gravitation force. The location of model 2 rainwater storage on the upper part of the first floor enables its water to serve the ground floor level and partly first floor, whereas, the location of rainwater storage of model 1 only allows its water to serve the ground floor level functions. As a result, these two models may not allow full integration of rainwater into the household building functions. On the other hand, model 3 and 4 have their one-level storage point in the roof headroom. The roof design allows model 3 storage to be filled by rainwater naturally through gravity while model 4 uses a low-pressure suction pump to draw water from the gutter to its storage. The location of models 3 and 4 storages allow their water to serve the first floor and second floor fully. Therefore, allowing their water to be fully integrated into the household functions.

The main demerit of these models is that limited space in the upper part of the building may limit the amount of rainwater harvested in households. This may be mitigated by the use of rectangular-shaped storage tanks which have a high capacity per storage ratio that allows more water to be stored within a limited space.

\section{Conclusions}

The study's assessment of RWH reticulation systems in household buildings highlighted that the means through which rainwater is moved in the system determines the level of integration of rainwater into household functions and the 
management cost spent on these systems. In a bid to optimize the functionality of rainwater, households have resulted in a two-level storage point RWH reticulation typologies 1, 2, 4 and 5 . The use of mechanically pressurized systems by these typologies makes them energy intensive which in turn increases the operation cost due to the energy cost spent on pumping of water in these systems. The two-level storage point also increases the number of elements in the systems to be serviced thus increasing the maintenance cost of the systems. Further analysis of the findings revealed that typology 6 with a one-level storage point supplied rainwater in the household via a pressurized system that relied on the gravitation force. Advanced RWH reticulation system allows its rainwater to be fully integrated into the household at the same time eliminating energy-related operation cost with minimal maintenance cost. Therefore, advanced RWH reticulation systems should be installed in households to reduce high management costs accrued by the installed RWH reticulation systems in household buildings in Nairobi County.

Based on the complexity of this study, samples were collected from five out of eighty-five neighbourhoods in Nairobi County. This study therefore, recommends that a study that samples more neighbourhoods in this county should be carried out for more comprehensive generalization of findings on RWH reticulation systems in household buildings. This study was mainly limited to single dwelling two-level household buildings in Nairobi County. The study recommends that a similar study be conducted in multi-storey commercial buildings and multi-dwelling unit buildings. This will help in collection of overall information on RWH reticulation systems installed in buildings for optimum conservation of both water and energy resources in built environment in urban areas.

\section{Acknowledgements}

The author would like to express his appreciation to all the consultants who funded this research through the Pharos Architects ltd lead, Water Conservation Fellowship.

\section{Conflicts of Interest}

The authors declare no conflicts of interest regarding the publication of this paper.

\section{References}

[1] Caleb, C.A., Rahman, A. and Gathenya, J. (2016) Economic Analysis and Feasibility of Rainwater Harvesting Systems in Urban and Peri-Urban Environments: A Review of the Global Situation with a Special Focus on Australia and Kenya.

[2] Vieira, A.S., Beal, C.D., Ghisi, E. and Stewart, R.A. (2014) Energy Intensity of Rainwater Harvesting Systems: A Review. Renewable and Sustainable Energy Reviews, 34, 225-242. https://doi.org/10.1016/j.rser.2014.03.012

[3] Wanyonyi, J.M. (2000) Rainwater Harvesting Possibilities and Challenges in Kenya. 
Kenya Rainwater Association.

[4] EPA (2000) Rain Water Harvesting, Conservation, Credit, Codes, and Costs, Literature Review and Case Studies.

[5] Campos, M.A.S and Amorim, S.V. (2003) Rainwater Harvesting in a Residential Tall Building in the City of Sao Carlos-Brazil.

[6] Ahmed, H. (2016) Machine and Process Management; How IIoT and "Smart Pumping" Can Contribute to Solving the Global Water Crisis. https://blog.se.com/machine-and-process-management/2016/03/14/iiot-smart-pum ping-can-contribute-solving-global-water-crisis/

[7] Butler, D., Melville, P.S. and Ward, S. (2016) Rainwater Harvesting Typologies for UK Houses: A Multi-Criteria Analysis of System Configurations. Water, 8, 129. https://doi.org/10.3390/w8040129

[8] Matos, C., Santos, C., Pereira, S., Bentes, I. and Imteaz, M. (2013) Rainwater Storage Tank Sizing: Case Study of a Commercial Building. International Journal of Sustainable Built Environment, 2, 109-118. https://doi.org/10.1016/j.ijsbe.2014.04.004

[9] WHO (2011) Guidelines for Drinking-Water Quality. 4th Edition, Potable Water Standards, Water Standards, Water Quality Standards and Guidelines. I. World Health Organization.

[10] Angrill, S., Farreny, R., Gasol, C.M., Gabarrell, X., Viñolas, B. and Josa, A. (2012) Environmental Analysis of Rainwater Harvesting Infrastructures in Diffuse and Compact Urban Models of Mediterranean Climate. The International Journal of Life Cycle Assessment, 17, 25-42. https://doi.org/10.1007/s11367-011-0330-6

[11] Kothari, C.R. (2009) Research Methodology: Methods and Techniques. New Age International (P) Ltd., New Delhi, India.

[12] NCIDP (2018) Nairobi County Integrated Development Plan 2018-2022.

[13] Maina, K.M. (2014) Assessment of the Challenges of Water Supply and Sanitation in Uncontrolled Residential Developments of Huruma Estate, Nairobi County. Bachelor's Degree, Nairobi University, Kenya, 20.

[14] CAWST (2011) Introduction to Household Rainwater Harvesting. Participant Manual.

[15] Barberán, R., Colás, D. and Egea, P. (2019) Water Supply and Energy in Residential Buildings: Potential Savings and Financial Profitability. https://doi.org/10.3390/su11010295

[16] Roebuck, M., Dumbrava, C.O. and Tait, S. (2011) Whole Life Cost Performance of Domestic Rainwater Harvesting Systems in the United Kingdom. Water and Environment Journal, 25, 355-365. https://doi.org/10.1111/j.1747-6593.2010.00230.x

[17] Dijk, S.V. (2018) Performance Assessment of Citywide Rainwater Harvesting Strategies in New York City. Supplementary Information. 